This item was submitted to Loughborough's Research Repository by the author.

Items in Figshare are protected by copyright, with all rights reserved, unless otherwise indicated.

\title{
Prevalence of work-related musculoskeletal disorders in agriculture workers in Korea and preventative interventions
}

PLEASE CITE THE PUBLISHED VERSION

https://doi.org/10.3233/WOR-193038

\section{PUBLISHER}

IOS Press $(9)$ The Authors

\section{VERSION}

AM (Accepted Manuscript)

\section{PUBLISHER STATEMENT}

The final publication is available at IOS Press through https://doi.org/10.3233/WOR-193038.

\section{LICENCE}

CC BY-NC-ND 4.0

\section{REPOSITORY RECORD}

Kee, Dohyung, and Roger Haslam. 2019. "Prevalence of Work-related Musculoskeletal Disorders in Agriculture Workers in Korea and Preventative Interventions". figshare. https://hdl. handle.net/2134/37028. 
Prevalence of work-related musculoskeletal disorders in agriculture workers in Korea and preventative interventions

\section{Abstract}

BACKGROUND: Work-related musculoskeletal disorders (WMSDs) are estimated to be the most common and frequent of all occupational diseases in agriculture in Korea, but the full extent of the problem has yet to be surveyed.

OBJECTIVE: This paper presents the results of a survey investigating the extent of WMSDs among self-employed farmers in Korea. It also describes ergonomics based preventive interventions initiated by the Korean government.

METHOID: The prevalence of WMSDs was surveyed among 358 farmers using a questionnaire adapted from the Nordic questionnaires, employing three case definitions.

RESULTS: The results showed that the overall prevalence rates of WMSDs by case definition 1 (any symptoms), 2 (symptoms with a pain intensity of moderate or greater), and 3 (symptoms with a pain intensity of high or greater) were $97.2 \%, 83.2 \%$, and $39.7 \%$ respectively and that the shoulder, knee and lower back disorder rates were higher than those of other body parts. Compared to the prevalence rates of WMSDs for workers in other industries in Korea as well as USA farmers, the overall rates for farmers in Korea were much higher. The interventions, which adopted a participatory approach involving government, farmers, ergonomics, technical and industrial hygiene experts, showed benefits in terms of work efficiency, safety and farmer satisfaction.

CONCLUSIONS: The high WMSD symptom prevalence showed that agriculture is one of the most hazardous industries in Korea, and the Korean government's interventions were effective and successful.

Keywords: Nordic questionnaire; WMSDs; ergonomics interventions; participatory ergonomics; 


\section{Introduction}

The agriculture industry has a prominent role to play in achieving economic growth and reducing poverty [1]. However, it is also one of the most hazardous industries in developing and developed countries in terms of worker injury rates and poor occupational health, including work-related musculoskeletal disorders (WMSDs). The industrial accident rate of the agriculture industry in Korea was $0.94 \%$ in 2015 , which was much higher than the mean for all Korean industries (0.50\%) [2]. Farmers frequently have to adopt awkward, undesirable postures for long durations and subsequently suffer from discomfort or pain in various body parts, particularly the lower back, neck, and knee regions $[3,4]$. Some agricultural activities are not only difficult in terms of physical effort but are also prolonged, with farmers working $>8$ hours per day, especially during the planting and harvesting seasons. During these busy times, workers are engaged with their activities from early morning to dusk, often without adequate rest [5]. Farmers also exposed to extreme weather conditions (low and high temperature, severe rain and wind, etc.), and farm machinery related body vibration and high frequency noise contributing to spinal pain [4]. As such, agricultural workers involved in labor-intensive practices are exposed to a multitude of WMSD risk factors.

Three main risk factors of priority in the agriculture industry are: lifting and carrying heavy loads (>22.5 kg), sustained or repeated full body bending (stooping) and highly repetitive hand work (clipping, cutting) [5,6,7,8 ]. Consequently, WMSD incidence ranks among the highest of all industries. According to the International Labor Organization, around 160 million work-related illnesses per year occur worldwide among which WMSDs feature prominently, with extensive occupational health and economic consequences [9]. The high incidence of WMSDs leads to serious social problems, including wage compensation, medical expenses, reduced productivity, in addition to workers' physical and psychological pain $[10,11,12,13]$. Economic losses due to WMSDs in Korea are estimated to be about 1.3 trillion won ( 1 billion USD), which amounts approximately to $0.3 \%$ of the country's gross national product [14].

Another problem in the agriculture industry is that some of the work is performed by vulnerable groups including female workers and the elderly [15]. In 2016, the farming household population of Korea was 2,496,406, accounting for approximately $5 \%$ of the country's population [16]. Females accounted for a slightly higher proportion (51.06\%) than males $(48.94 \%)$ in agriculture [17], while the female/male ratio in the national population is almost equal $(50.09 \%$ vs $49.91 \%$ ) [18]. The ratio of farming household members aged $\geq 65$ years was high in 2015 (38.42\%), almost double the United Nation's criterion for a hyper- 
aged society (20\%) [19]. Moreover, the percentage of farmers aged $\geq 65$ years is expected to increase even further as Korea is experiencing unprecedented population aging.

Based on these trends of an aging population and increasing number of female farmers, it is estimated that WMSDs are the most common and frequent of all occupational diseases in agriculture in Korea. The full extent of the problem, however, has yet to be determined. A survey by the Korean government, confined to the WMSD status of employees of corporate agricultural companies and excluding self-employed farmers, found that among 68,697 employees, 21 WMSD cases occurred in 2015 [2]. However, the majority of farmers in Korea are self-employed. One study did survey the status of WMSDs for self-employed farmers in Korea, but the sample size was too small (greenhouse farmers, 34; paddy farmers, 56) to enable generalization of the results [20].

In Korea, the WMSD incidence rates in industries including agriculture increased from 1999 to 2003 , with the increase jumping rapidly in 2002 and 2003. Responding to the high WMSD incidence rates, the Korean government established a law prescribing employers' duty of preventing WMSDs in 2002, which became effective in July, 2003 [21]. In 2008 the Rural Development Agency (RDA), an affiliation of the Ministry of Agriculture, Food and Rural Affairs, recognized the need to reduce farmers' high workload, especially among elderly and female farmers. The RDA initiated two independent ergonomics based interventions to reduce farmers' workloads and to prevent agricultural injuries including WMSDs: (i) equipment intervention: providing accessible, easy to use, beneficial agricultural equipment and (ii) safety controls intervention: safety controls for farming activities tailored to particular crops [22, 23].

The present study aimed to investigate the prevalence of WMSDs in self-employed farmers to establish a more detailed picture of the extent of WMSDs in the agriculture industry of Korea. In order to establish the characteristics and status of WMSDs for Korean farmers, more detailed analyses have been conducted. These include investigating the relationships between WMSD prevalence and independent variables such as demographic and work variables, comparing WMSD symptom prevalence of Korean farmers with that of other industries and USA farmers. A second aim was to introduce Korean government-initiated ergonomics interventions intended to reduce farmers' workloads and to prevent agricultural injuries including WMSDs, and to evaluate the satisfaction levels, work efficiency improvement, effectiveness, etc. of the interventions. 


\section{Methods}

\subsection{WMSD survey}

\subsubsection{Participants}

Three hundred and fifty-eight farmers (278 males, 80 females) participated voluntarily in the WMSD symptom survey. The participants were recruited from farmers participated in cooperative unit's meetings or agricultural education and training events for the governmentinitiated ergonomics interventions. Study participants were engaged in combined agriculture, consisting of fruit tree or greenhouse farming, together with paddy farming, the most common farming type in Korea [20]. Thus the majority of participants were engaged in fruit tree or greenhouse farming as well as paddy farming. The crop types included apple, jujube, peach, water or oriental melon, cucumber and grape.

\subsubsection{Questionnaires and data collection}

A questionnaire adapted from the Nordic questionnaires [24] was used as the diagnostic tool. Prior to participating, participants were informed of the purpose and procedures of the investigation and provided informed consent. The survey was conducted during cooperative unit's meetings or during agricultural education and training events in 2014 and 2015. The first half of the questionnaire covered demographic and work characteristics. The demographic information collected included sex, age, height and body weight. The work characteristics included crop type, daily work hours, agriculture industry service history, and current crop cultivation duration. The latter part of the questionnaire focused on WMSD symptoms, including symptom frequency, duration and intensity by body part (neck, shoulder, arm/elbow, hand/wrist, fingers, upper/lower back, hip, thigh, knee, and ankle/foot).

\subsubsection{WMSD definitions}

The WMSDs were classified based on frequency, duration and intensity of relevant symptoms (pain, aches, stiffness, numbness, burning, swelling or tingling). We used three definitions of WMSD cases [24, 25, 26, 27]:

Definition 1: symptom duration of at least 1 week or occurring at least once a month for the last 12 months and a pain intensity of light or greater;

Definition 2: symptom duration of at least 1 week or occurring at least once a month for the last 12 months and a pain intensity of moderate or greater; 
Definition 3: symptom duration of at least 1 week or occurring at least once a month for the last 12 months and a pain intensity of higher or greater.

\subsubsection{Data analysis}

Descriptive data for 358 participants were obtained for demographic and work characteristics and WMSD status. WMSD symptoms were tabulated according to case definitions and body regions. The chi-square test was used to investigate the relationships between WMSD prevalence rates and the demographic and work characteristics independent variables. In applying the chi-square test, continuous variables such as age, height, weight, and service duration were categorized into three to seven groups (Table 1). All analyses were conducted using SAS (SAS Inc., NC, USA) and Microsoft Excel (Microsoft Co., WA, USA).

\subsection{Ergonomics interventions}

\subsubsection{Participants}

The interventions were evaluated with 247 farmers, 195 and 52 participants for the equipment and safety controls interventions respectively. Some of the 195 participants had also previously been involved in the WMSD survey. The participants were recruited from the farming villages or organizations where the lead author acted as consultant in support of the interventions.

\subsubsection{Questionnaires}

The evaluations for the equipment and safety controls interventions were undertaken at least one month after equipment or tools offered by the interventions had been distributed and used, in 2008-2017 and 2016-2017, respectively. The evaluations were done using questionnaires incorporating 5-point Likert scales. The questionnaire for the equipment intervention consisted of five questions covering: work efficiency improvement, reduction of fatigue due to work, necessity of the intervention project, effectiveness of the project and satisfaction with the project. The questionnaire for the safety control intervention also comprised five similar questions covering: work safety improvement, safety awareness improvement, necessity of the intervention project, effectiveness of the project and satisfaction with the project. 


\title{
3. WMSD survey results
}

\subsection{Demographic and work characteristics}

Details of the survey including participants' age, height, weight, agriculture industry work duration, current crop cultivation duration and daily working hours are summarized in Table 1. Means and standard deviations for the participants' physical characteristics were as follows: age, $55.7 \pm 9.0$ years; height, $1.659 \pm 0.075 \mathrm{~m}$; and weight, $64.7 \pm 7.9 \mathrm{~kg}$. Mean years of farming service and current crop cultivation were 28.8 and 22.6 years respectively. Mean daily work duration was $9.0 \pm 2.3$ hours. The proportions of $5-10$ and $\geq 10$ daily work hours were $48.6 \%$ and $48.0 \%$, respectively, which means that most farmers worked $\geq 5$ hours per day. Crop types included water or oriental melon (31.3\%), apple (26.8\%), jujube (18.4\%), grape (12.6\%), peach (5.6\%), and cucumber (5.0\%) (Figure 1).

\author{
[ Insert Table 1 around here ] \\ [ Insert Figure 1 around here ]
}

\subsection{WMSD symptoms}

The 12-month WMSD symptom prevalence was obtained based on the questionnaire survey for 358 participants. The sample size of the survey for case definitions 1 and 2 was found to be sufficiently large to achieve the accuracy of the confidence level of $95 \%$ and the acceptable limit of error of $5 \%$ (See Table 2). The sample size for case definition 3 was a little low. The sample size statistically required was calculated using the following equation [28]:

Sample size $(\mathrm{n}) \geq \hat{p}(1-\hat{p})\left(\mathrm{z}_{\alpha / 2} / \mathrm{d}\right)^{2}$

where $\hat{p}$ is the estimated symptom prevalence rate (\%) (maximum WMSD prevalence rate, i.e., overall symptom rate in Table 3 ), $\alpha$ is the significance level, $z_{\alpha / 2}$ is a value of a standard normal random variable such that $P\left(Z>Z_{\alpha / 2}\right)=\alpha / 2$, and $d$ is the acceptable limit of error(\%). 
The 12-month WMSD prevalence data are presented in Table 3 by body region and case definition. Analysis of variance showed that the WMSD rates varied significantly according to body regions and case definition $(p<0.001)$. Of the symptoms meeting case definition 1 , those in the shoulder $(77.1 \%)$ were the most prevalent, followed by the knee $(68.2 \%)$, lower back $(58.7 \%)$ and arm/elbow (55.3\%). The shoulder and knee WMSD rates were much higher than those of other body parts. The symptoms meeting case definition 2 were most frequent in the shoulder $(55.3 \%)$, followed by the knee $(50.3 \%)$, lower back $(43.0 \%)$ and neck $(39.1 \%)$. Of the symptoms meeting case definition 3 , the knee $(19.0 \%)$ exhibited the highest prevalence, followed by the lower back (17.3\%) and shoulder (11.7\%). Irrespective of case definition, the hip showed the lowest prevalence of symptoms, followed by the thigh. The overall 12-month prevalence of WMSDs with symptoms in at least one body site by the three case definitions were $97.2 \%, 83.2 \%$, and $39.7 \%$, respectively.

[ Insert Table 3 around here ]

\subsection{Relationship between prevalence and independent variables}

The relationships between overall WMSD symptom prevalence and the independent variables were examined using the chi-square test. The independent variables included gender, age, height, body weight, body mass index (BMI), farming experience, current crop experience, daily work hours and crop type. Body weight and daily work hours were significantly associated with prevalence for case definition $1(p<0.05)$; body weight, height and crop type were significantly associated with prevalence for case definition $2(p<0.05)$; and body weight and daily work hours were significantly associated with prevalence for case definition 3 ( $p<0.05)$. Across all three case definitions, body weight was the only independent variable that was significantly associated with WMSD prevalence $(p<0.05)$.

The WMSD symptom prevalence rates by body weight and case definition are shown in Figure 2. Since only four participants weighed $\geq 80 \mathrm{~kg}$, the $70-79 \mathrm{~kg}$ and $\geq 80 \mathrm{~kg}$ groups were merged into $a \geq 70 \mathrm{~kg}$ group. Although there was no consistent trend in prevalence according to body weight, the $\geq 70 \mathrm{~kg}$ group showed the lowest WMSD symptom prevalence. 


\subsection{Comparison with symptom prevalence of other industries and USA farmers}

The WMSD symptom prevalence of farmers in Korea was compared to those of other Korean workers for whom data were available in the following occupations: motor company workers [29, 30], ship building workers [31], subway train repair plant workers [32], dentists [33], disabled infant and children care center workers [34], general hospital nurses [35]. Comparison was also made with USA farmers and agriculture employees [36, 37, 38], and rice farmers of West Bengal, India [39] (Table 4). Case definition 1 was used for the comparison because many of the previous studies adopted this criterion. Among body parts, the thigh was excluded from the comparison because it was not investigated in the other studies.

As shown in Table 4, the overall and body part-specific WMSD symptom prevalence in Korean farmers was generally much higher than for workers from the other occupations. Specifically, WMSDs of the shoulder, arm/elbow, hand/wrist, fingers, hip, knee, and ankle/foot were all more frequent among the farmers, with the neck and low back prevalence only greater for dentists and subway train repair workers, respectively. On the other hand, the WMSD symptom rate for the upper back was the lowest of all industries compared. Moreover, compared to USA farmers, the WMSD prevalence in Korean farmers was much higher for all body parts except for the hip; in fact, the prevalence for the shoulder and knee was more than five and two times higher, respectively. More Indian farmers suffered the WMSD symptoms than Korean and USA farmers except for the shoulder.

[ Insert Table 4 around here ]

\section{Ergonomics interventions}

The Korean government initiated ergonomics intervention projects targeting farming villages or organizations with 10-30 farmers. A requirement was that an ergonomics, mechanical technology, industrial hygiene or safety expert participated in every farming village or organization as a consultant to support the implementation of the interventions. The lead author of this paper [Edited for Review Process] participated as a consultant to 1-5 village/organization intervention projects every year during the projects implementation period. 


\subsection{Equipment intervention}

In 2008 the RDA initiated the offering of financial support for projects to provide farmers with small, accessible, easy to use, beneficial agricultural equipment, specific to particular cultivated crops. The funding continued until 2017. The equipment included manual or powered carts, one-, three-, four-wheeled, or with caterpillar tracks; grass cutters; pest control machines; conveyors; and lifts, for cultivating water melons, oriental melons, grapes, apples, cucumbers, jujube and peaches. These projects have provided approximately US\$44,444 (W50,000,000) for each farming village or organization and funded 131-185 farming villages or organizations a year, amounting to a total of US\$65,951,000 for 1,484 villages or organizations by 2017 (Table 5).

\section{[ Insert Table 5 around here ]}

\subsubsection{Agriculture equipment procurement process}

The procurement of the equipment consisted of four components. Firstly, small agricultural equipment that was appropriate for farming villages or organizations was selected according to the farming activity risk factors. At this stage, typically one or two items of equipment were selected. Secondly, a company manufacturing the equipment types selected was identified based on their product's usability, safety and economic efficiency, as well as the company's willingness to revise the equipment further. Thirdly, the equipment was revised to improve usability, safety, economic efficiency, function, durability and exterior design. The revisions focused on components such as the controls, control box, displays, cargo box and grips/handles rather than the entire system. The projects then required the farming villages or organizations to buy the revised agricultural equipment for their crops or farming environment instead of purchasing an existing product on the open market. Fourthly, the villages or organizations introduced and used the revised equipment in their farming activities, with evaluation undertaken of workload, perceived discomfort or fatigue, subjective satisfaction and other factors. At this point, short training sessions for the equipment were provided by the manufacturer or provider. All of the above procedures were guided by ergonomics or technology experts' input. It was mandatory for an ergonomics or technology expert to participate in every supported village or organization (in return for $10 \%$ of the project's cost). Representative examples of equipment revisions developed by the author are shown in Table 6. Other equipment revisions by other ergonomics or technology experts were similar in nature to the examples given in Table 6. 
[ Insert Table 6 around here ]

\subsubsection{Project evaluation}

The mean evaluation scores for 4 of the 5 questions exceeded 4.3 (Figure 3), indicating that the farmers who participated in the project experienced work efficiency improvement and considered the project necessary and effective. The farmers also had high overall satisfaction with the project. The score for fatigue reduction was lower (3.5) compared to others, but it can be interpreted as moderate indication that there was fatigue reduction.

[ Insert Figure 3 around here ]

\subsection{Safety controls for farming activities}

This project began with a pilot, demonstrator intervention, running for 3 years from 2015 until 2017. The project was customized to the crops cultivated by the participating farmers and provided approximately US $\$ 44,444(\$ 50,000,000)$ funding for each farming village chosen by the RDA. The project has been implemented for 60-85 villages every year (2015: 60; 2016, 2017: 85). Whether the project will be continued after 2017 depends on the assessment results for the 3-year pilot.

\subsubsection{Safety controls intervention process}

The element of the project consisted of four main stages. Firstly, a work analysis by crop type was performed, which included examining monthly crop-growing phases and analyzing agricultural work activities by phase, work duration, materials handled, etc. Secondly, the potential for farming activity injuries was surveyed and the risk factors for each potential injury were identified and classified according to four main aspects: human, machine, mediating factors (e.g. materials, environment), and managerial. The risk assessment for each potential injury type was based on frequency and severity. Thirdly, possible solutions to avoid potential injuries were developed and evaluated according to their effectiveness, efficiency, and applicability. Finally, an improvement plan for the assessed farming activities was implemented, prioritized according to degree of risk. The improvement plan included providing small and inexpensive equipment or safety guards; education on safe working postures and methods; visits to more advanced villages or agricultural machine manufacturing factories etc. Unlike the equipment intervention, this project allowed farmers to purchase commercial equipment or tools directly in the marketplace. Examples of the equipment available were racks for farming tools; agricultural chemical sprayer; pest control 
machine; grass mower; pruning shears; stools for seated work; protective clothing; safety gloves and shoes; hats; goggles; dust or gas masks; protective pads for back, shoulder, knee; storage box for pesticide etc (Figure 4). The improvements are expected to be reevaluated, with a further iteration, to identify any additional possibilities for improvement. An ergonomics, industrial hygiene or safety expert was required to participate in the projects for each supported village (in return for $15 \%$ or more of the project's cost). The four main stages of the project generally took 6-10 months depending upon the characteristics of the chosen crops.

[ Insert Figure 4 around here ]

\subsubsection{Safety controls intervention evaluation}

The evaluation found that the mean scores for all 5 questions exceeded 4.1(Figure 5). This implies that the participants considered there had been benefits with the improvement of work safety, safety awareness, necessity and effectiveness of the project, and were satisfied with the project overall.

[ Insert Figure 5 around here ]

\section{Discussion and conclusions}

This study investigated the 12-month WMSD symptom prevalence among farmers in Korea and the government initiated ergonomics interventions implemented to prevent their occurrence. The overall rates by case definitions 1,2 , and 3 were $97.2 \%, 83.2 \%$, and $39.7 \%$, respectively. Of body regions, the shoulder, knee, and low back showed higher WMSD symptom prevalence rates, followed by the arm/elbow, neck, hand/wrist and fingers. The higher prevalence of the shoulder, knee and low back WMSD may be attributed to the frequent use of these body parts. This is inferred from the following: 1) Farming activities in Korea such as harvesting, lifting, and carrying are less mechanized than in advanced countries, such as USA and Western European countries, and are performed manually instead of being mechanized; 2) Harvesting crops requires farmers to adopt stooped trunk postures, often for significant periods of time [36, 40]; 3) Many activities such as weeding 
and harvesting fruits cultivated on the ground as well as sorting fruits according to size and quality are conducted in awkward postures, such as squatting or kneeling, with a lack of working tables and chairs. These activities are known to be significant risk factors for WMSDs [36, 41, 42].

This study found that the relationships between the overall WMSD symptom prevalence for case definition 1 and the demographic and work characteristics independent variables were not significant except for body weight and daily work hours. This finding is in partial agreement with the findings of Collins and O'Sullivan [43], Kee and Seo [35], Lusted et al. [44], Smith et al. [45, 46], Widanarko et al. [47] and Yip [48]. These studies indicated that age, height, weight, BMI, and nursing and current ward experience were not significantly related to the prevalence rates of WMSDs in nursing. In other occupations, studies of footwear industry workers [49], nurses [50] and Iranian sewing machine operators [51] reported that individual factors including age, sex and BMI and work-related factors such as number of years worked and prolonged working hours per shift were associated with WMSD symptom prevalence, in contrast with this study's findings. The variation found in relationships between WMSD outcomes and demographic and work characteristics for different occupations is not surprising. Different occupations involve different tasks and work organization and, consequently, risk exposures for WMSDs.

In the present study, there was no consistent relationship between body weight and WMSD symptom prevalence for the sample as a whole. Of the three body weight groups, however, the heaviest group ( $\geq 70 \mathrm{~kg}$ ) experienced significantly lower rates than the other groups for all three case definitions. A possible explanation for this is that heavy farmers with body weights $\geq 70 \mathrm{~kg}$, have greater muscle strength, allowing them to cope better with lifting and carrying heavy objects performed without mechanical aids.

Since the definitions of WMSD symptoms and body regions used in this study differed slightly from those of relevant previous studies, it is difficult to compare directly the prevalence rates found in this study to those of other industries in Korea or the USA. However, most of the existing studies adopted definitions of WMSD symptoms that were similar to case definition 1 in this study. Comparing on this basis, the WMSD symptom prevalence overall and for most body parts was much higher among the Korean farmers than for other Korean occupations. This again highlights that agriculture is particularly hazardous in this respect [5]. Furthermore, the WMSD prevalence for almost all body parts was higher for Korean farmers than for USA farmers. This may be attributed to lower levels of mechanization, a high dependence on manual labor for many activities and an increased 
proportion of female and elderly farmers compared to the USA [42].

It is generally the case in WMSD surveys that overall symptom prevalence increases with the number of body parts investigated. This study included all body parts in the analysis, whereas the other studies of Korean motor company workers, subway train maintenance plant workers and nurses, as well as USA farmers, did not. As this study investigated the WMSD prevalence for more body parts than the other studies, it is possible this might have contributed to the higher overall WMSD prevalence rate found by us. Because of this, conclusions from the comparisons should be interpreted with caution.

It is clear that agricultural jobs and related activities threaten the health of farmers. Ergonomics, then, has an important role to play in health promotion and injury prevention among farm workers [15]. Farmers, however, are generally not aware that the risk factors involved in their work can be addressed with ergonomics [52]. To ensure interventions are a success, ergonomics expertise and a participatory approach to intervention development and implementation are prerequisites [53]. The interventions need the right practitioners to be involved, because the void in the design process between user requirements to reduce workplace risk factors for WMSDs and the practitioners of agricultural tools/equipment should be addressed [54, 55]. An ergonomics approach is helpful and appropriate to determine the mismatch between people capacity and system demand [56]. Without worker participation, interventions are much less likely to be practical or acceptable [57]. In addition, given the variation in agricultural practices, interventions need to be focused on crop-specific tasks [52]. It is also known that adherence to ergonomics in design together with a full assessment of work systems would help reduce work-related MSDs [58]. From this perspective, the Korean government's initiatives to improve farming practices, consisting of a participatory approach involving government, ergonomics experts and farmers, focused on specific crop related activities, were carefully designed to be both effective and successful. Thanks to the careful design, the Korean government ergonomic intervention has been evaluated affirmatively by the farmers participated in the intervention, though a systematic literature review showed that most interventions in agriculture had not a clear positive effect [59]. The rewards from adopting an ergonomics approach to the interventions should include a more efficient production process, lower labor costs, reduced injury-related absences and turnover, decreased expenditures for medical care and worker compensation and a reduced ill-health burden attributable to musculoskeletal injuries [52].

Methodological limitations of this study should be acknowledged. The WMSD survey and evaluations for the equipment and safety controls interventions were performed with 
constrained sample sizes. The evaluations for the ergonomics interventions were mostly qualitative rather than quantitative. Notwithstanding, the research has provided data on the prevalence of WMSDs in agriculture of Korea and demonstrated the benefits of two government initiated ergonomics interventions.

\section{Acknowledgement}

This work was supported by the Ministry of Education of the Republic of Korea and the National Research Foundation of Korea (NRF-2017R1D1A1B03028532).

\section{References}

[1] FAO, The state of food and agriculture 2010-2011: Women in agriculture-Closing the gender gap for development. Rome: FAO; 2011.

[2] Ministry of Employment and Labor. Industrial accidents analysis. Seoul(Korea): Ministry of Employment and Labor; 2016.

[3] Gangopadhyay S, Das B, Das T, Ghoshal G. An ergonomic study on posture-related discomfort among preadolescent agricultural workers of West Bengal, India. International Journal of Occupational Safety \& Ergonomics. 2005;11:315-22.

[4] Raczkiewicz D, Saran T, Sarecka-Hujar B, et al. Work conditions in agriculture as risk factors of spinal pain in postmenopausal women. International Journal of Occupational Safety and Ergonomics. 2017; published online.

[5] Meyers JM, Miles JA, Faucett J, et al. Ergonomics in agriculture: workplace priority setting in the nursery industry. American Industrial Hygiene Association Journal. 1997;58:121-26.

[6] Fathallah FA. Musculoskeletal disorders in labor-intensive agriculture. Applied Ergonomics. 2010;41:738-43.

[7] Meyers JM, Miles JA, Faucett J, Janowitz I, Tejeda TG, Duraj V, Kabashima J, Smith R. High risk tasks for musculoskeletal disorders in agricultural field work. In: Proceedings of the IEA 2000/HFES 2000 Congress; 2000 July 31-Aug 4; San Diego, CA; 2000. P. 3616-3-619.

[8] Meyer, JM, Miles JA, Tejeda DG, Janowitz I, Tejeda TG, Kabashima JN. Priority risk factors for back injury in agricultural field work: Vineyard ergonomics. Journal of Agromedicine. 2001.;8:37-52. 
[9] Niu, S. Ergonomics and occupational safety and health: An ILO perspective. Applied Ergonomics. 2010;41:744-53.

[10] Ayoub MM, Mital A. Manual Materials Handling. London: Taylor \& Francis; 1989.

[11] Bao SS, Kapellusch JM, Merryweather AS, Thiese MS, Garg A, Hegmann KT, Silverstein BA. Relationships between job organisational factors, biomechanical and psychosocial exposures. Ergonomics. 2016;59:179-94.

[12] Chaffin DB, Andersson GBJ, Martin BJ. Occupational Biomechanics. 3rd ed. New York (NY): John Wiley \& Sons, Inc.; 1999.

[13] Grzywinski W, Wandycz A, Tomczak A, et al. The prevalence of self-reported musculoskeletal symptoms among loggers in Poland. International Journal of Industrial Ergonomics. 2016;52:12-7.

[14] Lee I. Psychophysical evaluation of whole-body postural stresses based on discomfort for body joint motions [dissertation]. Pohang(Korea): POSTECH; 2002.

[15] Naeini HS, Karuppiah K, Tamrin SB, et al. Ergonomics in agriculture: An approach in prevention of work-related musculoskeletal disorders (WMSDs). Journal of Agriculture and Environmental Science. 2014;3:33-51.

[16] KOSIS [Internet]. Deajeon(Korea): Statistics Korea; [cited 2017a Mar 15]. Available from:

http://kosis.kr/statisticsList/statisticsListIndex.do?menuld=M_01_01\&vwcd=MT_ZTITLE \&parmTabld=M_01_01\&parentld=F.1;F_5.2;F_5_1.3;F_5_1_1.4.

[17] KOSIS [Internet]. Deajeon(Korea): Statistics Korea; [cited 2017b Mar 15]. Available from:

http://kosis.kr/statHtml/statHtml.do?orgld=101\&tblld=DT_1YL20041\&vw_cd=MT_GTITL E01\&list_id=101_01\&seqNo=\&lang_mode $=$ ko\&language $=$ kor\&obj_var_id $=\& i t m \_i d=\& c o$ nn_path=MT_GTITLE01.

[18] KOSIS [Internet]. Deajeon(Korea): Statistics Korea; [cited 2017c Mar 15]. Available from:

http://kosis.kr/statHtml/statHtml.do?orgld=101\&tblld=DT_1IN1603\&vw_cd=MT_ZTITLE \&list_id=A11_2016_10\&seqNo=\&lang_mode=ko\&language=kor\&obj_var_id=\&itm_id=\& conn_path=MT_ZTITLE.

[19] KOSIS [Internet]. Deajeon(Korea): Statistics Korea; [cited 2017d Mar 15]. Available from:

http://kosis.kr/statisticsList/statisticsListlndex.do?menuld=M_01_01\&vwcd=MT_ZTITLE \&parmTabld=M_01_01\&parentld=F.1;F_4.2;MT_CTITLE_m.3;MT_CTITLE_m_2015.4; MT_CTITLE_m_2015_20.5;\#SelectStatsBoxDiv. 
[20] Hwang K-M. Comparison of musculo-skeletal disorders and health related quality of life using EQ-5D according to agricultural type [master's thesis]. Jeongub(Korea): Wonkwang University; 2009.

[21] Kee D, Chung MK, Kim J-H. Legal system and its effect for prevention of work-related musculoskeletal disorders in Korea. International Journal of Industrial Ergonomics. 2011;41:224-32.

[22] Rural Development Agency. Support of convenient equipment for improving environment of agricultural activities. Suwon(Korea): Rural Development Agency; 2015a.

[23] Rural Development Agency. Consulting plan for pilot project of safety control for agricultural activities customized by crops. Suwon( Korea): Rural Development Agency; 2015b.

[24] Kuorinka I, Jonsson B, Kilbom A, Vinterberg H, Biering-Sorensen F, Andersson G, Jorgensen $\mathrm{K}$. Standardized Nordic questionnaires for the analysis of musculoskeletal symptoms. Applied Ergonomics. 1987;18:233-7.

[25] Bernard B, Sauter S, Lawrence F, Petersen M. Job task and psychosocial risk factors for work-related musculoskeletal disorders among newspaper employees. Scandinavian Journal of Work Environment and Health. 1994; 20:417-26.

[26] Josephson M, Lagerstrom M, Hagberg M, Hjelm EW. Musculoskeletal symptoms and job strain among nursing personnel: a study over a three-year period. Occupational and Environmental Medicine. 1997;54:681-5.

[27] NIOSH. NIOSH health hazard evaluation report[Report No. HETA 89-250-2046]. Melville, New York, USA: Newsday, Inc.; 1990.

[28] Kim YD, Kim YC, Park BY, et al. Introduction to statistics. $5^{\text {th }}$ ed. Seoul(Korea): Youngji Moonhwa Sa; 2008.

[29] Choi S, Kim H, Kim T, Park D. A study on job stress and MSDs (musculoskeletal disorders) of workers at automotive manufacturing industry. Journal of Ergonomics Society of Korea. 2005;20(3):202-11.

[30] Noh YM, Yang JJ. The risk factors and prevalence of musculoskeletal symptoms for the research worker in an automobile company. Journal of Korean Society of Occupational and Environmental Hygiene. 2003;13:226-33.

[31] Koo BE, Park KS, Kim CH. Analysis of musculoskeletal disorders for labor of unstandardization work; on the subject of the centering-work in a shipbuilding industry. Journal of Ergonomics Society of Korea. 2007;26(2):113-22.

[32] Kim CH, Kwon YJ, Paik SR, et al. Study of musculoskeletal disorders at a subway train repair plant in Korea. Journal of Ergonomics Society of Korea. 2004;23(3):121-34. 
[33] Cha J, Ryu T, Choi HW, Lee J-B, Kim M-K, Chung M.K., Jeong C. Survey of musculoskeletal disorders in Korean dentists. Journal of Ergonomics Society of Korea. 2007;26:137-47.

[34] Lee JT, Seo SY, Shin YC, et al. Evaluation of work-related musculoskeletal risk factors in disabled infants and children care centers. Journal of Korean Society of Occupational and Environmental Hygiene. 2004;14:18-26.

[35] Kee D, Seo SR. Musculoskeletal disorders among nursing personnel in Korea. International Journal of Industrial Ergonomics. 2007;37:207-12.

[36] Davis KG, Kotowski S. Understanding the ergonomic risk for musculoskeletal disorders in the United States agricultural sector. American Journal of Industrial Medicine. 2007;50:501-11.

[37] Gomez MI, Hwang S, Stark AD, May JJ, Hallman EM, Pantea CI. An analysis of selfreported joint pain among New York farmers. Journal of Agricultural Safety \& Health. 2003;9(2):143-57.

[38] Guo HR, Tanaka S, Halperin WE, Cameron LL. Back pain prevalence in U.S. industry and estimates of lost workdays. American Journal of Public Health. 1999;89:1029-35.

[39] Das B. Gender differences in prevalence musculoskeletal disorders among the rice farmers of West Bengal, India. Work. 2015;50:229-40.

[40] NIOSH, Simple solutions: Ergonomics for farm workers[Report No. 2001-111]. Cincinnati, USA: DHHS(NIOSH) Publications; 2001.

[41] Holmberg S, Thelin A, Stiernstrom E, Svardsudd K. The impact of physical work exposure on musculoskeletal symptoms among farmers and rural non-farmers. Annals of Agricultural and Environmental and Medicine. 2003;10:179-84.

[42] Lee KS. The importance of agricultural ergonomics. Journal of Ergonomics Society of Korea. 2011;30:437-41.

[43] Collins JD, O'Sullivan LW. Musculoskeletal disorder prevalence and psychosocial risk exposures by age and gender in a cohort of office based employees in two academic institutions. International Journal of Industrial Ergonomics. 2015;46:85-97.

[44] Lusted MJ, Carrasco CL, Mandryk JA, et al. Self-reported symptoms in the neck and upper limbs in nurses. Applied Ergonomics. 1996;27:381-7.

[45] Smith DR, Atkinson R, Kubo H, et al. A comparison of musculoskeletal disorders among female nursing-home nurses in Japan and Korea. Ergonomics Australia. 2002;16:16-9.

[46] Smith DR, Kondo N, Tanaka E, Tanaka H, Hirasawa K, Yamagata Z. Musculoskeletal disorders among hospital nurses in rural Japan. The International Electronic Journal of Rural Remote Health Research, Education, Practice and Policy. 2003;3(3):1-7. 
[47] Widanarko B, Legg S, Stevenson M, et al. Prevalence of musculoskeletal symptoms in relation to gender, age, and occupational/industrial group. International Journal of Industrial Ergonomics. 2011;41:561-72.

[48] Yip YB. A study of work stress, patient handling activities and the risk of low back pain among nurses in Hong Kong. Journal of Advanced Nursing. 2001;36:794-04.

[49] Vieira ER, Serra MVGB, de Almeida LB, et al. Symptoms and risks for musculoskeletal disorders among male and female footwear industry workers. International Journal of Industrial Ergonomics. 2011;41:561-72.

[50] Heiden B, Weigl M, Angerer P, Müller A. Association of age and physical job demands with musculoskeletal disorders in nurses. Applied Ergonomics. 2013;44:652-8.

[51] 9. Dianat I, Kord M, Yahyazade P, Karimi MA, Stedmon AW. Association of individual and work-related risk factors with musculoskeletal symptoms among Iranian sewing machine operators. Applied Ergonomics. 2015;51:180-8.

[52] ResearchGate [Internet]. Berlin(German): ResearchGate; [cited 2017 Mar 15]. Available from:

https://www.researchgate.net/publication/242117872_Ergonomics_and_Musculoskeletal _Injuries_in_Agriculture_Recognizing_and_Preventing_the_Industry's_Most_Widesprea d_Health_and_Safety_Problem

[53] Hagg GM. Corporate initiatives in ergonomics-an introduction. Applied Ergonomics 2003;34:3-15.

[54] Broberg O, Edwards K. User-driven innovation of an outpatient department. Work. 2012;41:101-6.

[55] Punchihewa HKG, Gyi D. Reducing work-related musculoskeletal disorders (MSDs) through design: Views of ergonomics and design practitioners. Work. 2016:53;127-42.

[56] Meyer F, Eweje G, Tappin D. Ergonomics as a tool to improve the sustainability of the workforce. Work. 2017;57:339-50.

[57] Hignett S, Wilson JR, Morris W. Finding ergonomic solutions- participatory approaches: In-depth review. Occupational Medicine. 2005;55(3):200-7.

[58] Buckle P. Ergonomics and musculoskeletal disorders: Overview. Occupational Medicine. 2005;55(3):164-7.

[59] Nilsson K. Interventions to reduce injuries among older workers in agriculture: A review of evaluated intervention projects. Work. 2016:55;471-80. 


\section{List of Tables}

Table 1. Demographic and work characteristics $(n=358)$

Table 2. Minimum sample size for overall symptom rates by case definition

Table 3. WMSD prevalence by body region and case definition (\%)

Table 4. Comparison of work-related musculoskeletal disorder prevalence in Korean farmers versus those in other industries and countries

Table 5. Number of villages funded and their expenses

Table 6. Revision examples 
Table 1. Demographic and work characteristics $(n=358)$

\begin{tabular}{|c|c|c|c|}
\hline & $\begin{array}{l}\text { Mean } \\
\text { (Standard } \\
\text { deviation) }\end{array}$ & Range & Distribution \\
\hline Age & $55.7(9.0)$ years & $31-89$ years & $\begin{array}{l}<40 \text { years: } 6.6 \% \\
40-49 \text { years: } 22.4 \% \\
50-59 \text { years: } 36.9 \% \\
60-69 \text { years: } 29.1 \% \\
\geq 70 \text { years: } 5.0 \%\end{array}$ \\
\hline Height & $1.659(0.075) \mathrm{m}$ & $1.50-1.82 \mathrm{~m}$ & $\begin{array}{l}1.50-1.59 \mathrm{~m}: 20.8 \% \\
1.60-1.69 \mathrm{~m}: 42.4 \% \\
1.70-1.79 \mathrm{~m}: 32.1 \% \\
\geq 1.80 \mathrm{~m}: 4.7 \%\end{array}$ \\
\hline Weight & $64.7(7.9) \mathrm{kg}$ & $50-90 \mathrm{~kg}$ & $\begin{array}{l}50-59 \text { kg: } 24.4 \% \\
60-69 \text { kg: } 49.5 \% \\
70-79 \text { kg: } 22.4 \% \\
>80 \text { kg: } 3.7 \%\end{array}$ \\
\hline $\begin{array}{l}\text { Farming } \\
\text { experience }\end{array}$ & 28.8(12.7) months & $2-60$ years & $\begin{array}{l}<10 \text { years: } 7.3 \% \\
10-19 \text { years: } 12.8 \% \\
20-29 \text { years: } 24.0 \% \\
30-39 \text { years: } 27.4 \% \\
40-49 \text { years: } 19.0 \% \\
50-59 \text { years: } 7.3 \% \\
>60 \text { years: } 2.2 \%\end{array}$ \\
\hline $\begin{array}{l}\text { Current crop } \\
\text { experience }\end{array}$ & 22.6(10.9) years & $2-50$ years & $\begin{array}{l}<10 \text { years: } 9.5 \% \\
10-19 \text { years: } 22.9 \% \\
20-29 \text { years: } 36.3 \% \\
30-39 \text { years: } 20.1 \% \\
40-49 \text { years: } 6.7 \% \\
>50 \text { years: } 4.5 \%\end{array}$ \\
\hline Daily work hours & $9.0(2.3)$ hours & $3-16$ hours & $\begin{array}{l}<5 \text { hours: } 3.4 \% \\
5-9 \text { hours: } 48.6 \% \\
\geq 10 \text { hours: } 48.0\end{array}$ \\
\hline
\end{tabular}


Table 2. Minimum sample size for overall symptom rates by case definition

\begin{tabular}{lcccc}
\hline & Case definition 1 & Case definition 2 & Case definition 3 \\
\hline $\begin{array}{l}\text { Overall symptom rate } \\
\begin{array}{l}\text { Minimum sample } \\
\text { required }\end{array}\end{array}$ & $97.2 \%$ & $83.2 \%$ & $39.7 \%$ \\
\hline${ }^{*}$ confidence level: $95 \%$, acceptable limit of error: $5 \%$ & 42 & 215 & 368 \\
\hline
\end{tabular}


Table 3. WMSD prevalence by body region and case definition (\%)

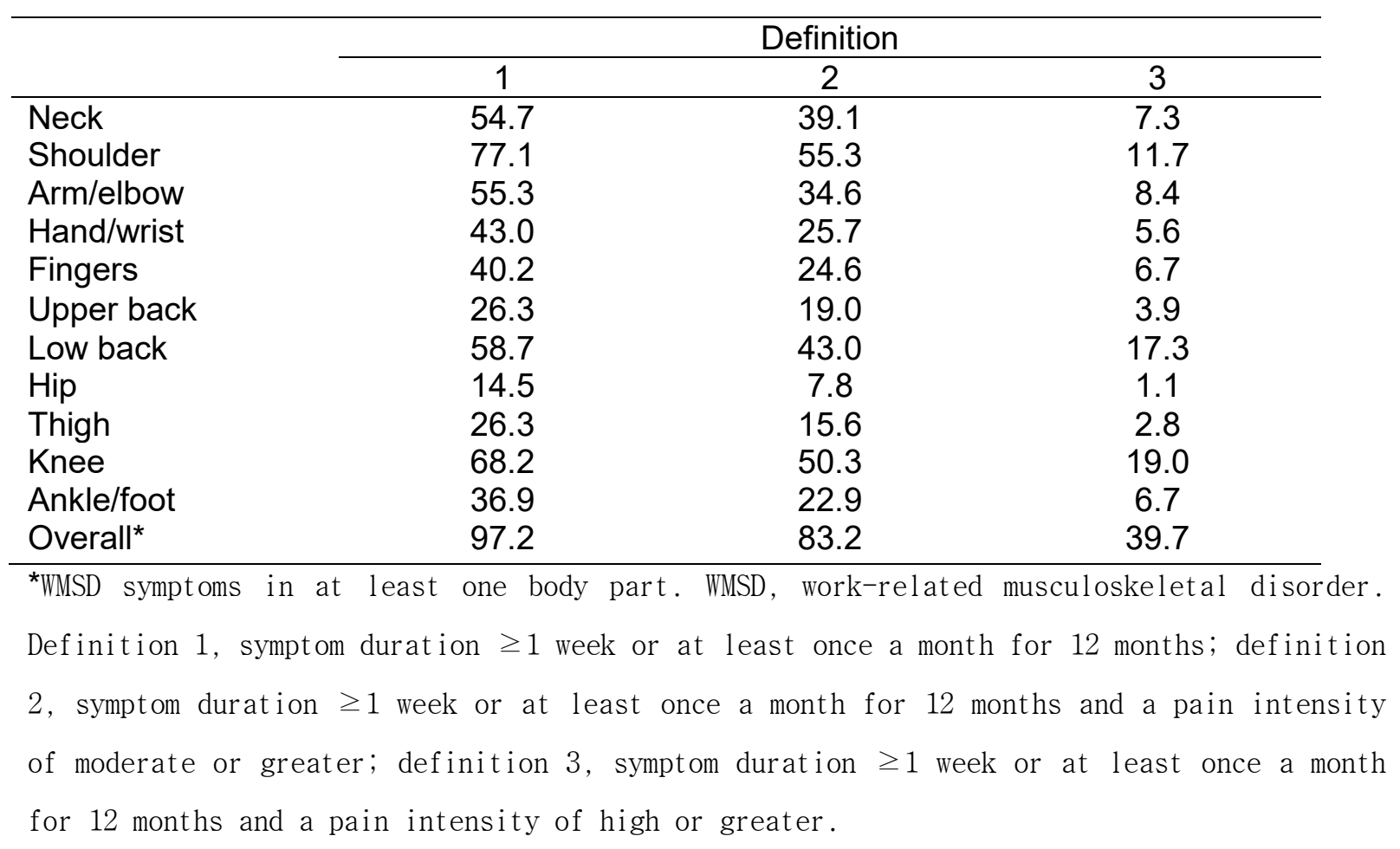


Table 4. Comparison of work-related musculoskeletal disorder prevalence in Korean farmers versus those in other industries and countries

\begin{tabular}{|c|c|c|c|c|c|c|c|c|c|c|}
\hline & $\begin{array}{l}\text { This } \\
\text { study }\end{array}$ & $\begin{array}{c}\text { Motor } \\
\text { company } \\
1(n=180)\end{array}$ & $\begin{array}{c}\text { Motor } \\
\text { company } \\
2(n=286)\end{array}$ & $\begin{array}{c}\text { Ship } \\
\text { building } \\
(n=120)\end{array}$ & $\begin{array}{l}\text { Subway } \\
(n=273)\end{array}$ & $\begin{array}{c}\text { Dentist } \\
(\mathrm{n}= \\
104)\end{array}$ & $\begin{array}{c}\text { Care } \\
\text { center } \\
(n= \\
123)\end{array}$ & $\begin{array}{c}\text { Nurse } \\
(n= \\
162)\end{array}$ & USA & $\begin{array}{l}\text { India }{ }^{\star \star *} \\
(n=220)\end{array}$ \\
\hline Neck & 54.7 & 47.9 & 17.2 & 16.3 & 45.1 & 82.3 & 40.7 & 17.3 & & \\
\hline Shoulder & 77.1 & 52.1 & 56.7 & 19.0 & 59.7 & 68.4 & 50.4 & 27.2 & $\begin{array}{c}14.0 \\
(n=122)\end{array}$ & 60.9 \\
\hline $\begin{array}{l}\text { Arm/ } \\
\text { elbow }\end{array}$ & 55.3 & 18.5 & 32.2 & 6.9 & 31.9 & & 18.7 & 7.4 & & \\
\hline $\begin{array}{l}\text { Hand/ } \\
\text { wrist }\end{array}$ & 43.0 & 26.2 & 36.7 & 10.9 & 38.1 & 43.0 & 38.2 & 2.6 & $\begin{array}{c}28.0 \\
(n=1,700)\end{array}$ & 53.6 \\
\hline Fingers & 40.2 & 26.2 & 36.7 & & 38.1 & & 38.2 & & & \\
\hline $\begin{array}{l}\text { Upper } \\
\text { back }\end{array}$ & 26.3 & & 36.1 & & & 46.0 & 50.4 & & & \\
\hline Low back & 58.7 & 35.3 & 36.1 & 23.8 & 66.7 & 55.7 & 50.4 & 23.4 & $\begin{array}{c}53.7^{*} \\
(\mathrm{n}=1,751)\end{array}$ & 93.8 \\
\hline Hip & 14.5 & & & & & & & 9.9 & $\begin{array}{c}15.0 \\
(n=1,706)\end{array}$ & \\
\hline Knee & 68.2 & 27.3 & & & 51.3 & & 24.2 & 24.7 & $\begin{array}{c}29.0 \\
(n=1,706)\end{array}$ & 80.9 \\
\hline $\begin{array}{l}\text { Ankle/ } \\
\text { foot }\end{array}$ & 36.9 & & & & 29.7 & & & 17.3 & & \\
\hline Overall & 97.2 & 66.4 & & & 86.8 & & & 56.8 & $\begin{array}{l}70^{* *} \\
(n=50)\end{array}$ & 99.0 \\
\hline
\end{tabular}

*Data for Polish female farmers; ${ }^{* *}$ : data for farm equipment operators; the numbers in parenthesis are the sample size investigated in the corresponding study 
Table 5. Number of villages funded and their expenses

\begin{tabular}{lccccccccccc}
\hline Year & 2008 & 2009 & 2010 & 2011 & 2012 & 2013 & 2014 & 2015 & 2016 & 2017 & Total \\
\hline $\begin{array}{l}\text { No of } \\
\text { villages }\end{array}$ & 131 & 147 & 135 & 143 & 141 & 140 & 185 & 160 & 164 & 138 & 1,484 \\
\hline $\begin{array}{l}\text { Expenditure } \\
\text { (US } \$ 1,000)\end{array}$ & 5,822 & 6,533 & 5,999 & 6,355 & 6,266 & 6,222 & 8,222 & 7,111 & 7,288 & 6,133 & 65,951 \\
\hline
\end{tabular}


Table 6. Revision examples

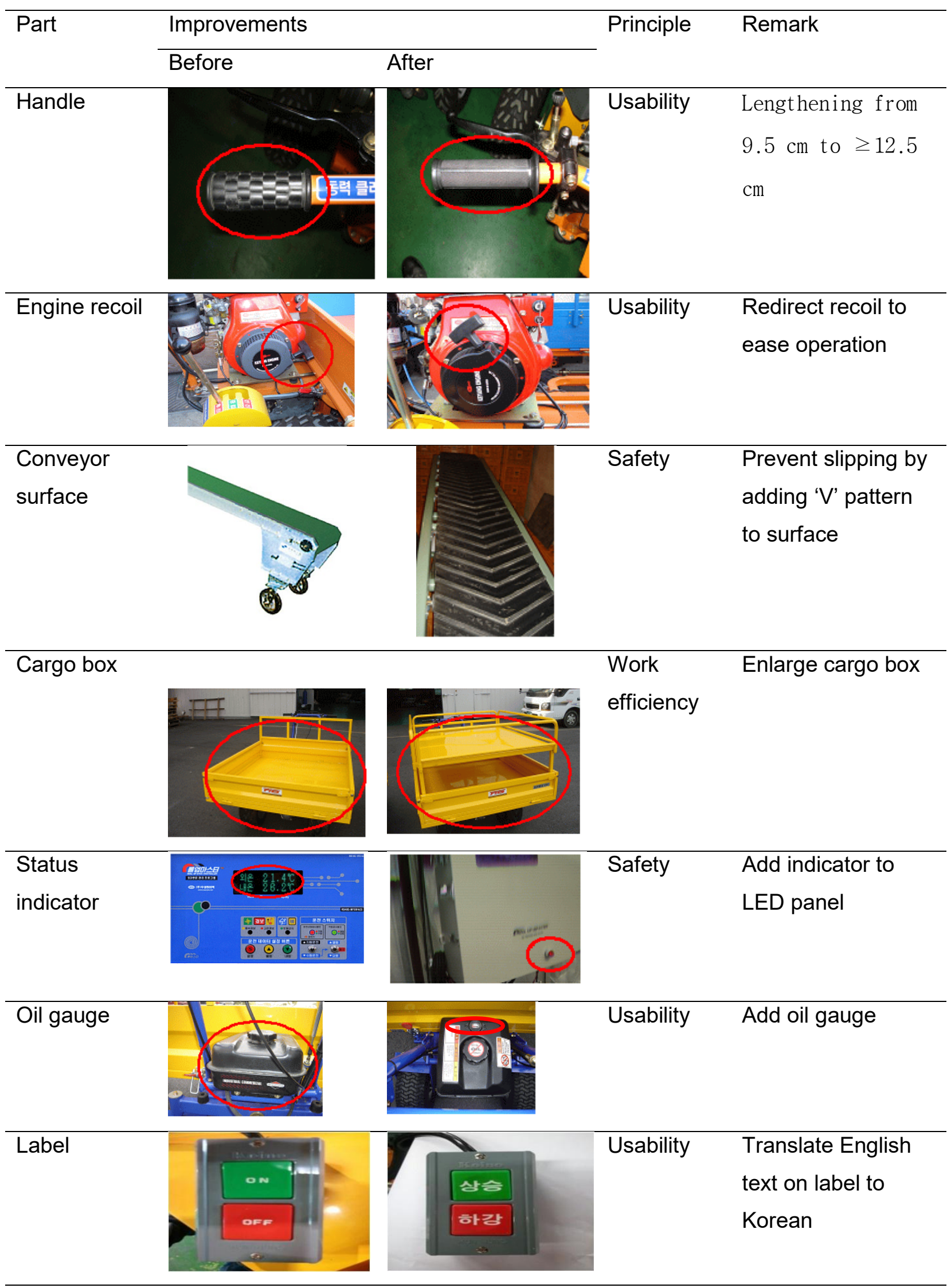




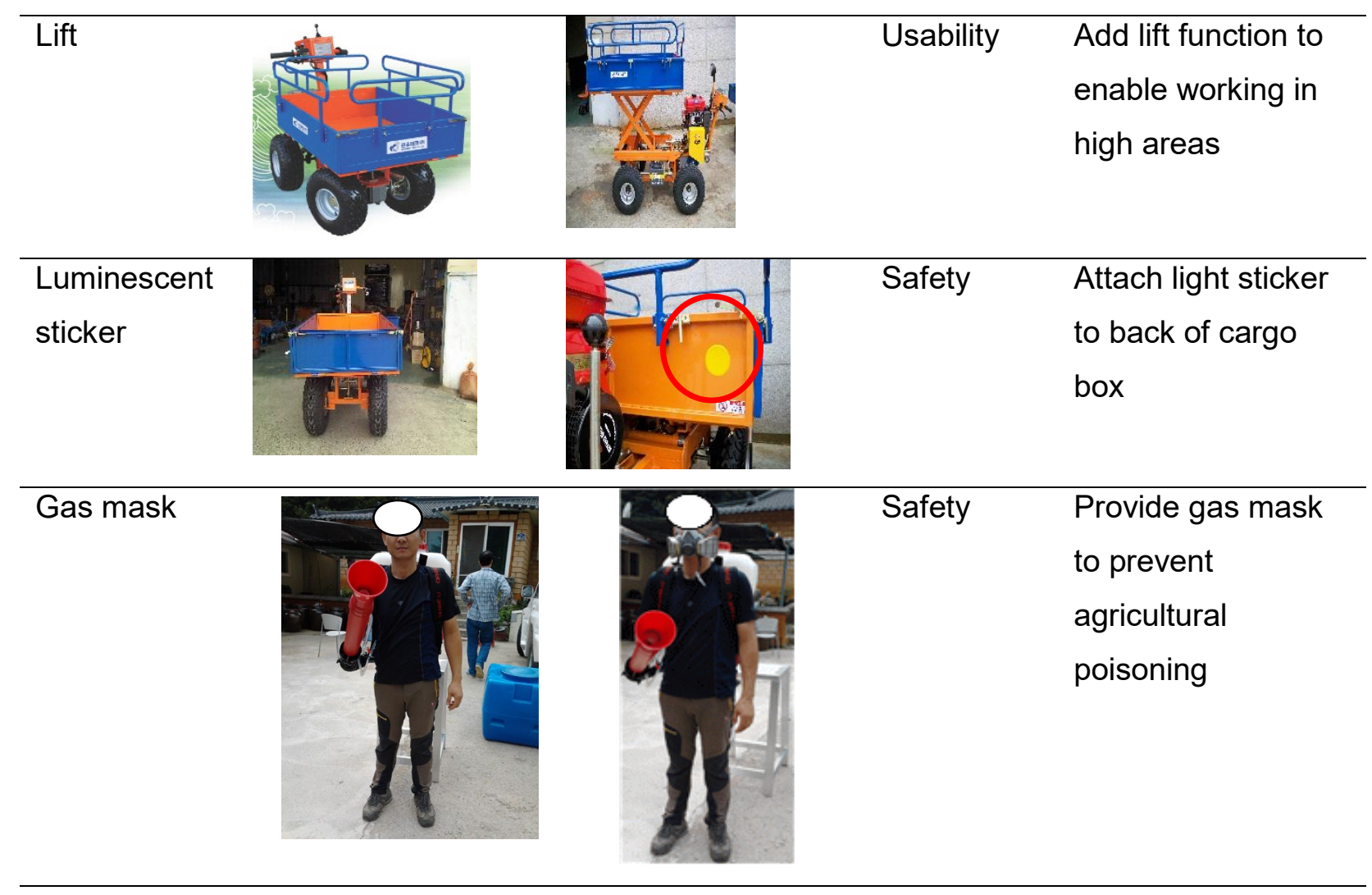




\section{List of Figures}

Figure 1. Distribution of crop types

Figure 2. Work-related musculoskeletal disorder symptom prevalence by body weight and definition

Figure 3. Mean evaluation scores for the equipment intervention

Figure 4. Examples of small equipment and safety guards

Figure 5. Mean evaluation scores for the safety controls intervention 


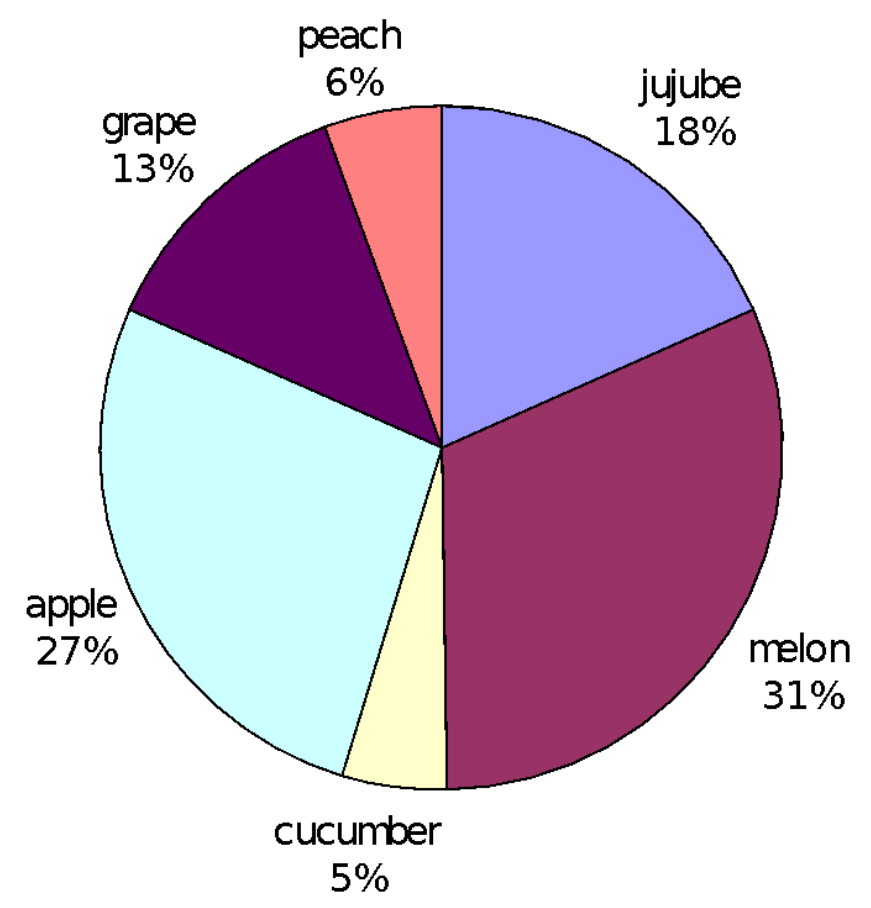

Figure 1. Distribution of crop types 


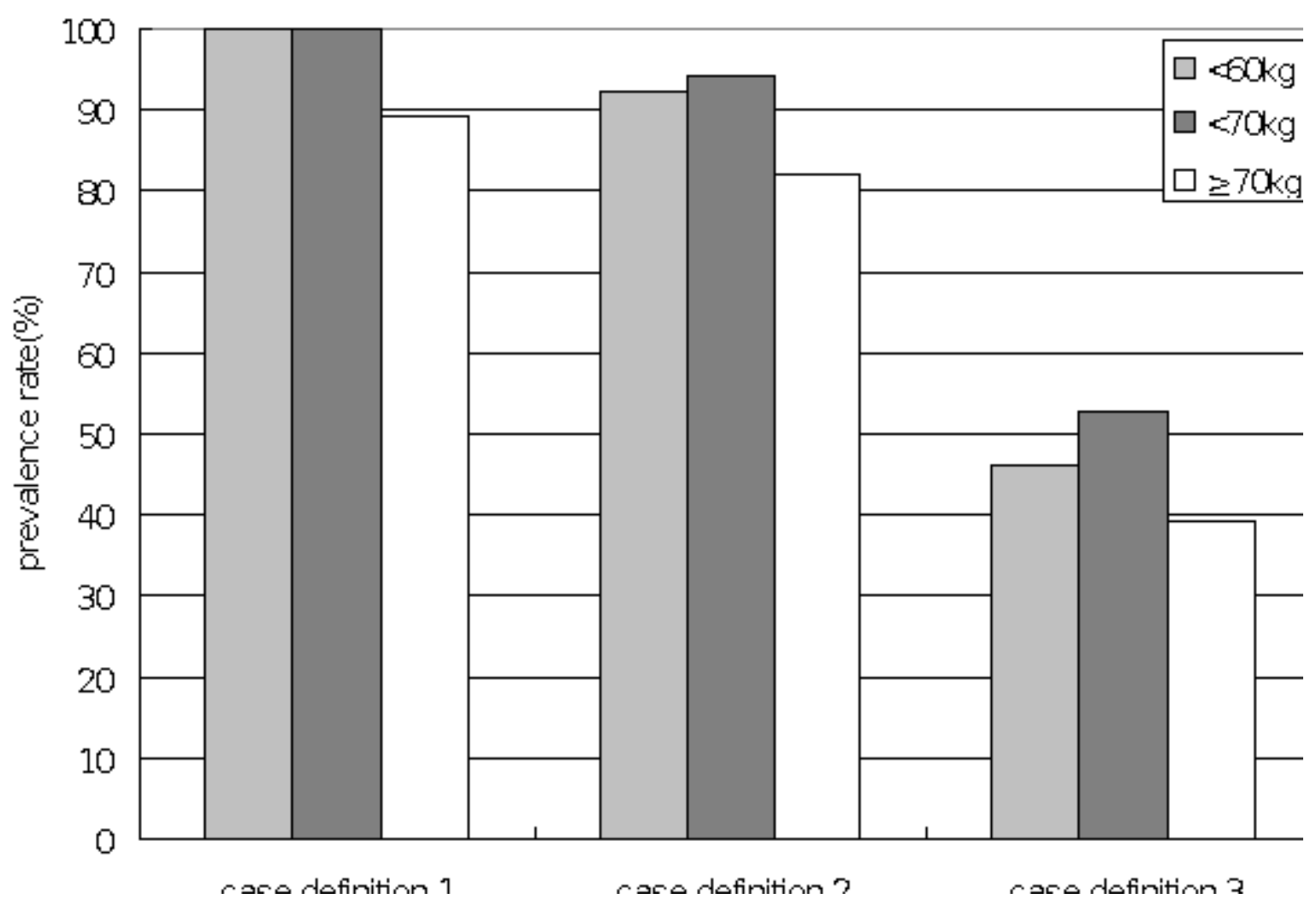

Figure 2. Work-related musculoskeletal disorder symptom prevalence by body weight and definition 


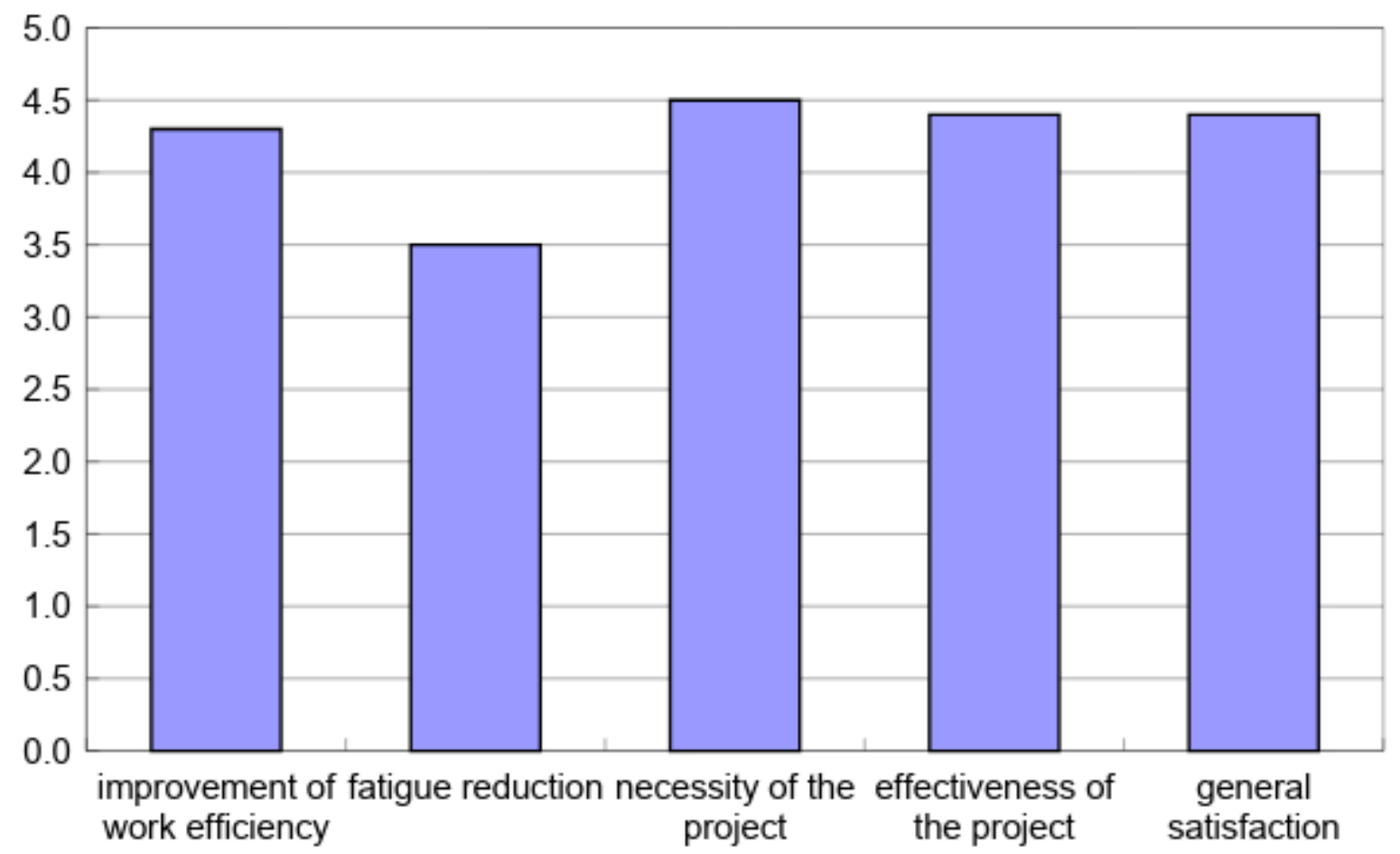

Figure 3. Mean evaluation scores for the equipment intervention 


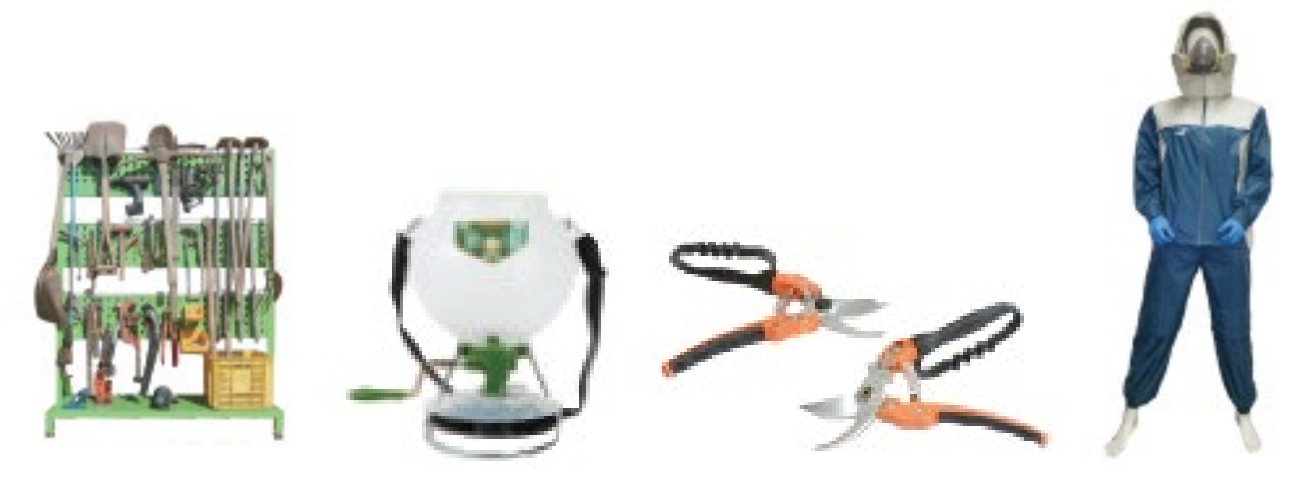
(a) rack for tools
(b) sprayer
(c) shear
(d) protective clothing

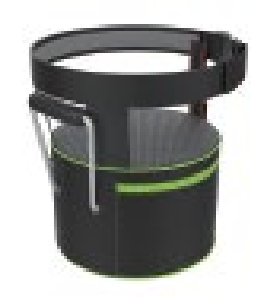

(e) stools

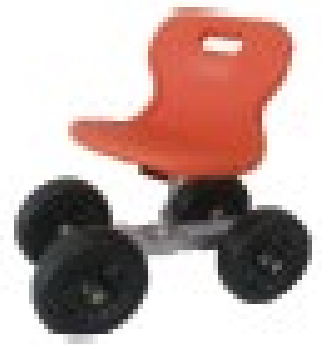

(f) farmer hat

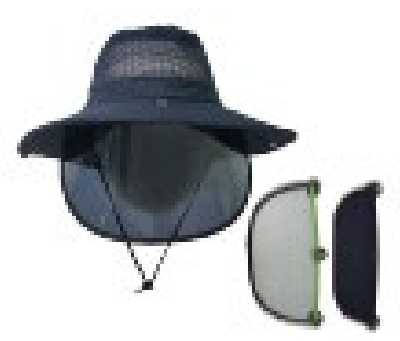

(g) dust mask

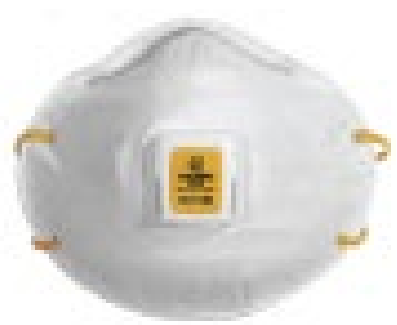

Figure 4. Examples of small equipment and safety guards 


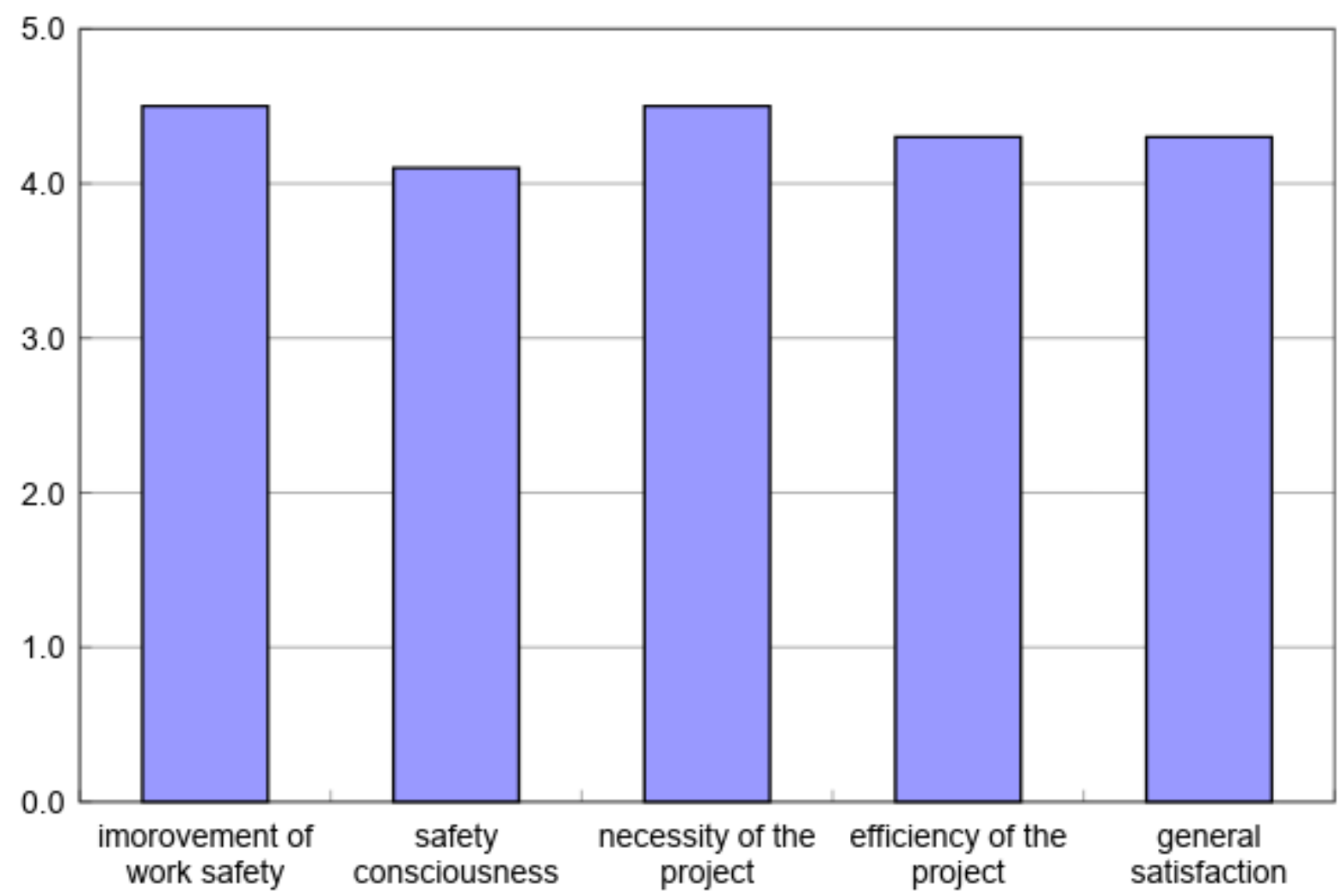

Figure 5. Mean evaluation scores for the safety controls intervention 